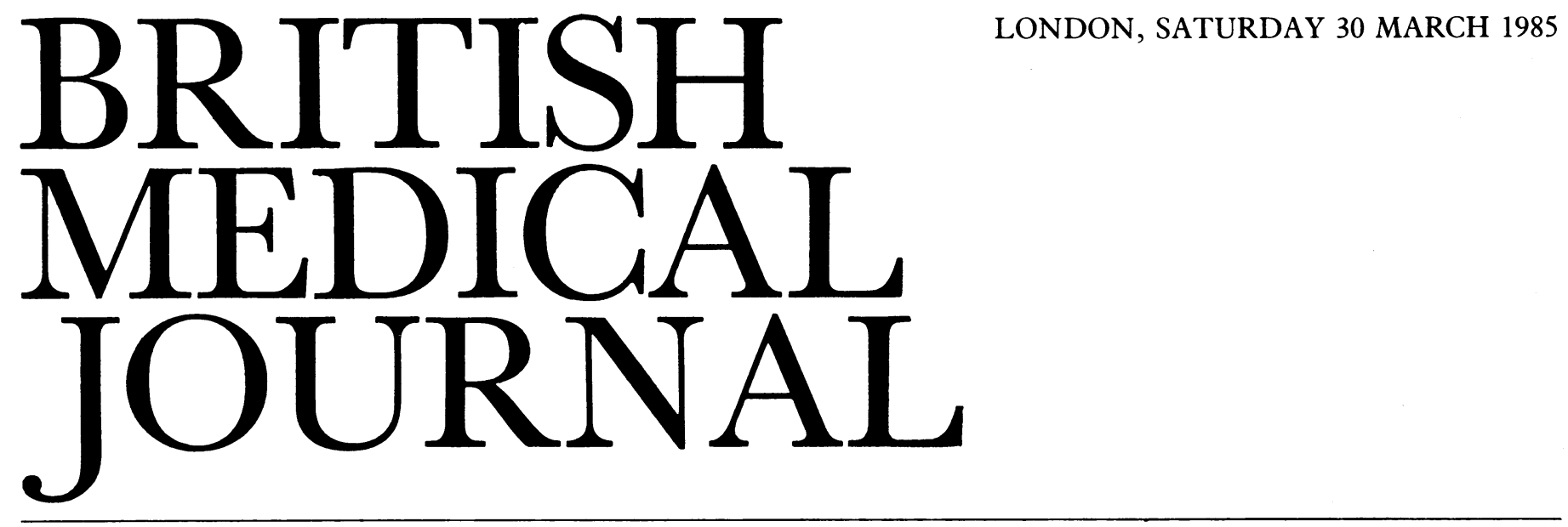

\title{
Dietary salt and hypertension: treatment and prevention
}

Despite the wealth of information on the relation between sodium and blood pressure the place of dietary restriction of salt in the treatment and prevention of essential hypertension remains controversial. There are two distinct questions. Firstly, does dietary salt restriction have anything to offer in the management of patients with established essential hypertension? Secondly, is there a case for reducing the salt intake of the general population in the hope that that would reduce the prevalence of essential hypertension and hence its complications?

Undoubtedly severe short term restriction of dietary salt intake (to around $10 \mathrm{mmol}(0.6 \mathrm{~g})$ a day from the normal British intake of around 140-200 mmol (8-12 g) a day) reduces blood pressure in patients with essential hypertension. ${ }^{12}$ The dietary measures required to achieve this effect ${ }^{34}$ are, however, unacceptable to most patients, ${ }^{1}$ and severe restriction of salt has not been shown to be safe.

The effects of moderate restriction of salt (to around 80 mmol $(4 \cdot 7 \mathrm{~g})$ a day) are less clear cut. Several groups have reported that moderate restriction is associated with a fall in blood pressure in patients with essential hypertension. ${ }^{5.10}$ The observed reduction in blood pressure in these studies cannot necessarily be attributed to restriction of salt, however, since it may have been caused by changes in other factors-particularly other constituents of the diet. For example, an increase in potassium intake appears to reduce blood pressure in both hypertensive ${ }^{11}$ and normotensive ${ }^{12}$ people, and in some studies potassium intake was deliberately increased in conjunction with restriction of sodium. ${ }^{7-10}$ Restriction of fats (particularly saturated fats) is also associated with a reduction in blood pressure in hypertensive and normotensive people. ${ }^{13}$ In most cases we do not know whether the dietary measures taken to reduce salt intake also reduced the fat intake, but in one study patients were deliberately asked to cut down fat. ${ }^{9}$ In the one study in which sodium intake was greatly reduced (from 192 to $77 \mathrm{mmol}$ $(11 \cdot 0-4 \cdot 4 \mathrm{~g})$ a day) without changes in other dietary constituents there was no consistent change in blood pressure, while a reduction in fat intake without reduction in salt intake was associated with a large fall in blood pressure. ${ }^{13}$ Finally, we do not know how far alterations in other dietary constituents such as calcium, alcohol, coffee, and meat, all of which influence the blood pressure, ${ }^{14-17}$ may have contributed to the reduction in blood pressure apparently due to restriction of salt.
In an attempt to circumvent these problems MacGregor and his colleagues carried out a double blind, randomised crossover comparison of sodium chloride and placebo in patient who took the same low sodium diet throughout the study. ${ }^{18}$ When they reduced their average sodium intake from 162 to $86 \mathrm{mmol}(9 \cdot 4$ to $5 \cdot 0 \mathrm{~g})$ a day their mean supine blood pressure fell by an average of $7 \cdot 1 \mathrm{~mm} \mathrm{Hg}$. Watt et al, however, were unable to reproduce these results using the same study design in general practice. ${ }^{19}$ Others have reported that moderate restriction of dietary salt does not reduce the blood pressure in patients with essential hypertension. ${ }^{20-22}$ Of course it may be that dietary restriction of salt may lower the blood pressure in some people and not in others ${ }^{23}{ }^{24}$; individual susceptibility may be determined in part by the responsiveness of the renin-angiotensin system ${ }^{25}$ and in part by genetic factors. ${ }^{26}$ Furthermore, any relation between daily intake of salt and blood pressure is unlikely to be linear, and there may be a "threshold" above which any change in intake of salt would not be expected to change the blood pressure appreciably. In conclusion, therefore, there is little to commend pure, moderate salt restriction for treating essential hypertension, though more complex dietary manipulation might be beneficial.

The suggestion that restriction of dietary salt should be adopted as a public health measure is based on the circumstantial evidence that intake of salt is causally related to essential hypertension. What is that evidence? Some of the numerous animal models of hypertension are dependent on salt, but their relevance to hypertension in man is dubious. ${ }^{24}$ Epidemiological studies have shown a positive correlation between average salt intake and blood pressure between different populations. ${ }^{27}$ Most $^{28}{ }^{29}$ but not all ${ }^{30}$ studies, however, have failed to show such a relation within a given population (for critical reviews see references 23 and 24). The reasons for this discrepancy are not clear-the apparent differences between populations might in fact be due to differences in other dietary and social factors, including

We apologise to readers for the late arrival of their journals. This is being caused by industrial action at the printers.

Readers are reminded that the $B M \mathcal{H}$ 's current classified job advertisements are also available on Prestel. 
adiposity; on the other hand, the failure to show a correlation within a population might be due to excessive "noise" in the data and the possibility that only certain individuals are susceptible to the effects of dietary salt. Lastly, circumstantial evidence suggests that a reduction in salt intake may be associated with a reduction in the incidence of stroke, but properly controlled prospective studies have not been carried out. ${ }^{31}$

The introduction of a policy of restriction of dietary salt in the population has been likened to the introduction of a new drug, requiring rigorous evaluation. ${ }^{32}$ Others have argued, however, that restriction of salt is more akin to the removal of a potentially noxious agent,${ }^{4}$ that it can therefore be advocated on the basis of much less rigorous criteria, and that we should immediately recommend widespread restriction of dietary salt, particularly since a reduction of the mean blood pressure of the population of only 2 or $3 \mathrm{~mm} \mathrm{Hg}$ could produce a relatively large benefit. ${ }^{33}$ This point of view depends heavily on the belief that moderate restriction of salt is completely harmless, but in the absence of evidence to the contrary we cannot ignore the possibility that wide scale moderate restriction of salt could lead to important adverse effects within the population.

The attractions of dietary measures for controlling a disease such as hypertension are obvious, but we believe that there is insufficient evidence to advocate the use of pure restriction of dietary salt in either the treatment or the prevention of essential hypertension. We need carefully controlled, long term, prospective intervention studies in large populations in order to determine the optimal level of dietary intake of salt and to evaluate the importance of other dietary factors, particularly potassium and fats-but most importantly to determine that any proposed measures are safe.

Clinical Lecturer in Cardiovascular Medicine,

N A BooN

John Radcliffe Hospital,

Oxford OX3 9DU

Clinical Reader (Wellcome Lecturer) and

J K ARONSON

Honorary Consultant in Clinical Pharmacology,

Radcliffe Infirmary,

Oxford OX2 6HE

1 Cameron DR, Dunlop DM, Platt R, Rosenheim ML, Sharpey-Schafer EP. The rice diet in the treatment of hypertension. A report to the Medical Research Council. Lancet in the treatment
1950;ii:509-13.

2 Watkin DM, Froeb HF, Hatch FT, Gutman AB. Effects of diet in essential hypertension. II. Results with unmodified Kempner rice diet in fifty hospitalized patients. Am $\mathcal{F}$ Med 150;9:441-93.

3 Altschul AM, Grommet JK. Food choices for lowering sodium intake. Hypertension 1982;34 (suppl III): 116-20.

4 MacGregor GA. Dietary sodium and potassium intake and blood pressure. Lancet 1983;i:750-3.

5 Parijs J, Joossens JV, van der Linden L, Verstreken G, Amery AKPC. Moderate sodium restriction and diuretics in the treatment of hypertension. Am Heart $\mathcal{f}$ 1973;85:22-34

6 Morgan T, Adam W, Gillies A, Wilson M, Morgan G, Carney S. Hypertension treated by salt restriction. Lancet 1978; i:227-30.

7 Parfrey PS, Vandenburg MJ, Wright P, et al. Blood pressure and hormonal changes following alteration in dietary sodium and potassium in mild essential hypertension. Lancet 1981; ; :59-63.

8 Holly JMP, Goodwin FJ, Evans SJW, Vandenburg MJ, Ledingham JM. Reanalysis of data in two Lancet papers on the effect of dietary sodium and potassium on blood pressure. Lancet 1981;ii:1384-7.

9 Beard TC, Cooke HM, Gray WR, Barge R. Randomized controlled trial of a no-addedsodium diet for mild hypertension. Lancet 1982;ii:455-8.

10 Skrabal F, Auböck J, Hörtnagl H. Low sodium/high potassium diet for prevention of hypertension: probable mechanisms of action. Lancet 1981;ii:895-900.

11 MacGregor GA, Smith SJ, Markandu ND, Banks RA, Sagnella GA. Moderate potassium supplementation in essential hypertension. Lancet 1982;ii:567-70

12 Khaw KT, Thom S. Randomized double-blind cross-over trial of potassium on bloodpressure in normal subjects. Lancet 1982;ii:1127-9.

13 Puska P, Iacono JM, Nissinen A, et al. Controlled, randomized trial of the effect of dietary fat on blood pressure. Lancet 1983;i:1-5.

14 Anonymous. Diet and hypertension [Editorial]. Lancet 1984;ii:671-3.

15 Potter JF, Beevers DG. Pressor effect of alcohol in hypertension. Lancet 1984; i: 119-22.

16 Freestone S, Ramsay LE. Pressor effect of coffee and cigarette smoking in hypertensive patients. Clin Sci 1982;63(suppl):403-5.

17 Rouse IL, Beilin LJ, Armstrong BK, Vandongen R. Blood-pressure-lowering effect of a vegetarian diet: controlled trial in normotensive subjects. Lancet 1983;i:5-10.
18 MacGregor GA, Markandu ND, Best FE, et al. Double-blind randomized crossover trial of moderate sodium restriction in essential hypertension. Lancet 1982;i:351-5.

19 Watt GCM, Edwards C, Hart JT, Hart M, Walton P, Foy CJW. Dietary sodium restriction for mild hypertension in general practice. $\mathrm{Br} \mathrm{Med} \mathcal{J}$ 1983;286:432-6.

20 Silman AJ, Locke C, Mitchell P, Humpherson P. Evaluation of the effectiveness of a low sodium diet in the treatment of mild to moderate hypertension. Lancet $1983 ; 1: 1179-82$.

21 Richards AM, Nicholls MG, Espiner EA, et al. Blood-pressure response to moderate sodium restriction and to potassium supplementation in mild essential hypertension. Lancet 1984; ; 757-6

22 Gillum RF, Elmer PJ, Prineas RJ, Surbey D. Changing sodium intake in children. The Minneapolis children's blood pressure study. Hypertension 1981;3:698-703.

23 Simpson FO. Salt and hypertension: a sceptical review of the evidence. Clin Sci 1979;57(suppl):463-80.

24 Swales JD. Dietary salt and hypertension. Lancet 1980;i:1177-9.

25 Parfrey PS, Markandu ND, Roulston JE, Jones BE, Jones JC, MacGregor GA. Relation between arterial pressure, dietary sodium intake, and renin system in essential hypertension. BrMed f 1981;283:94-7.

26 Anonymous. Genetics, environment, and hypertension [Editorial]. Lancet 1983;i:681-2.

27 Gleibermann L. Blood pressure and dietary salt in human populations. Ecology of Food and Nutrition 1983;2:143-56.

28 Simpson FO, Waal-Manning HJ, Bolli P, Phelan EL, Spears GFS. Relationship of blood pressure to sodium excretion in a population survey. Clinical Science and Molecular Medicine 1978;55(suppl);373-5.

29 Holden RA, Ostfeld AM, Freeman DH, Hellenbrand KG, D'Atri DA. Dietary salt intake and blood pressure. JAMA 1983;250:365-9.

30 Poulter N, Khaw KT, Hopwood BEC, Mugambi M, Peart WS, Sever PS. Salt and blood pressure in various populations. $\mathcal{f}$ Cardiovasc Pharmacol 1984;6(suppl): 197-203.

31 Joossens JV, Geboers J. Salt and hypertension. Prev Med 1983;12:53-9.

32 Brown JJ, Lever AF, Robertson JIS, et al. Salt and hypertension. Lancet 1984;ii:456.

33 Rose G. Strategy of prevention: lessons from cardiovascular disease. Br Med $f$ Rose G. Strategy
$1981 ; 282: 1847-51$.

\section{Chemotherapy of Hodgkin's disease comes of age}

Twenty one years ago came the first hint of successful chemotherapy in Hodgkin's disease.' A scheme called MOPP (mustine, vincristine, procarbazine, and prednisone) led to a remarkable number of lasting responses in metastatic Hodgkin's disease. The early results have been confirmed by many other studies, and MOPP or variations on the theme now give complete remissions in $60-80 \%$ of patients with advanced (stages III and IV) Hodgkin's disease. ${ }^{2}$ Half of those patients will become long term survivors, free of disease, and are probably cured. Alternating combinations of MOPP with other regimens claimed not to be cross resistant (doxorubicin, bleomycin, vinblastine, dacarbazine) may give even better results.

In the past decade oncologists have concentrated on selecting the best treatment for each individual patient based on the outcome of clinical trials. These trials have also allowed the substantiation of prognostic factors for groups of patients treated either with radiotherapy for limited disease or chemotherapy for more advanced disease. The age of the patient, the number of individual sites of affected lymph nodes, and the size of those lymph nodes-especially the mediastinal mass-all influence the response to radiotherapy in adults treated for Hodgkin's disease. Thus elderly patients with bulky disease particularly in the mediastinum or in multiple sites will do badly.

These factors (in addition to histological picture and stage of disease) are also important for the prediction of long term survival after chemotherapy. ${ }^{4}$ Patients with nodular sclerosis and lymphocyte depleted types do badly, and those with stage IV B do less well than those with stage III. Achievement of a complete remission is a self evident prognostic factor, though very good results may be obtained from salvage treatment for non-responders and those who relapse late either by applying another chemotherapy regimen or by giving local radiotherapy when appropriate.

The treatment of Hodgkin's disease brings in its wake a 